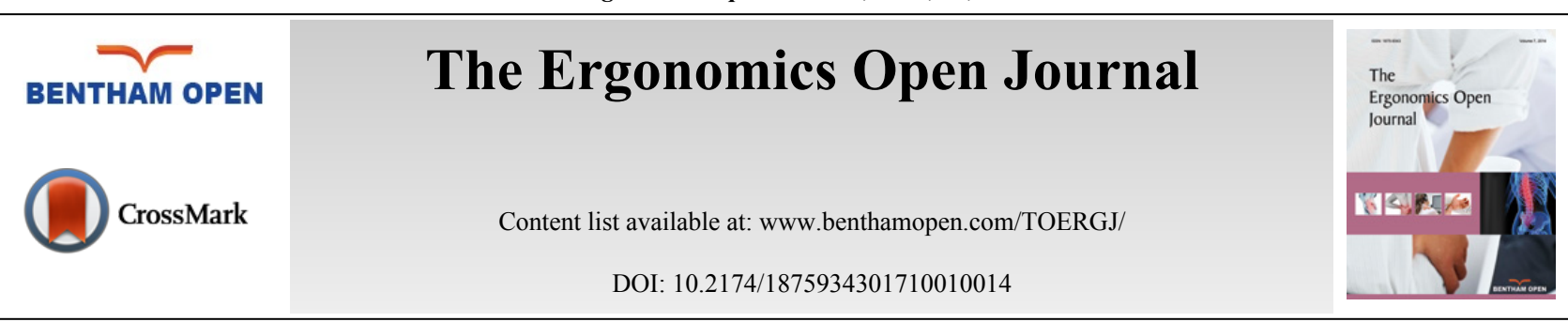

RESEARCH ARTICLE

\title{
Rating Comfort and Every-Day Mood States (TRIM-S): Comparing Likert Scales with Visual Analog Scales (VAS) and Relations to Cardiovascular Response
}

\author{
Michael Trimmel $^{1, *}$ and Karin Trimmel ${ }^{2}$ \\ ${ }^{1}$ Institute of Environmental Health, Center for Public Health, Medical University Vienna, Vienna, Austria \\ ${ }^{2}$ Department of Neurology, Medical University Vienna, Vienna, Austria
}

Received: May 17, 2017

Revised: July 19, 2017

Accepted: July 26, 2017

\begin{abstract}
:
Background:

In the attempt to quantify the impact of environmental aspects on the experience of humans, ratings on comfort and on mood are widely used but different answering formats are suggested.

\section{Objective:}

A direct comparison of different kinds of scale formats of ratings of comfort and of mood states as well as their relation to the cardiovascular response was the objective. It was expected that activation-related scales are associated with physiological measures and that comfort scales and ratings of mood states would give complementary information on the impact of environmental conditions.
\end{abstract}

\section{Method:}

The response to different answering formats of ratings of Trimmel's Index of Mood States (TRIM-S) and of overall comfort as well as their relation to the cardiovascular response (heart rate, HR, and heart rate variability, HRV) were compared in an experimental setting. Ratings on labelled four-point Likert scales, seven-point Likert-like scales, and visual analog scales (VAS) scales (filled in in a counterbalanced order across the 45 test persons) were compared in 5 min lasting conditions: baseline, positive situation, negative situation, boring situation, Touch for Health, and relaxation.

\section{Results:}

The four dimensions of TRIM-S (energy, good mood, motivation, and relaxation) showed a condition-specific pattern of response, widely independent of the answering format. Also ratings on overall comfort showed a condition specific response widely independent of the answering format. HR was high for Touch for Health and low for the boring condition. Relative power of high frequency in HRV (HF\%) was particularly associated with being bored and relaxation. Relative power in very low frequency in HRV (VLF\%) was inversely and more strongly related to conditions than relative power in low frequency in HRV (LF\%), and a certain sensitivity with emotional activation was observed in VLF\%. The activation related dimensions of TRIM-S, energy and relaxation, were associated with cardiovascular activity, but motivation and mood are more sensitively assessed on the subjective level of response by ratings, widely independent of the answering format.

\section{Conclusions:}

Results indicate that subjective responses by ratings and physiological measures are complementary in assessing the impact of environmental circumstances. To decide the appropriate answering format of the questionnaires, factors like target population,

\footnotetext{
* Address correspondence to this author at the Institute of Environmental Health, Center for Public Health, Medical University Vienna, Kinderspitalgasse 15, A 1090 Vienna, Austria; Tel: +4314016034901; E-mail: michael.trimmel@meduniwien.ac.at
} 
limitations of human information processing (suggesting to hold 4 elements in mind rather than the maximal capacity of about 7 elements which could challenge the person in the answering decision), and economical aspects should be considered.

Keywords: Ergonomics, Environment, Relaxation, Touch for Health, Assessment, Scales, Comfort, Mood, Affect, Heart rate, Heart rate variability.

\section{INTRODUCTION}

People are exposed to environmental circumstances all the time, regardless of work, leisure, or sleep. Main features of the environment are air quality, including odor, temperature, noise or sound, various chemical pollutions, and many other factors like radiation, electromagnetic fields, cosmic radiation, etc. Such conditions obviously affect the exposed person's mood, comfort, performance, or even health [1 - 5]. In addition, other environmental aspects like personal space, sitting equipment, and persons in the vicinity are also aspects of environmental conditions affecting humans. To optimise positive effects and to diminish the negative effects of designed environments or machines, the evaluation by ratings on comfort is widely applied, although theoretical considerations on comfort are diverse and topic-related [6 8]. Most often specific aspects of the environmental condition in question have to be rated on various scales, like for temperature [9, 10] or for humidity [11]. In addition, ratings of overall comfort may give further information and reflect a more general, personally integrated aspect of perceiving the environmental condition in question [12]. As a complementary method to ratings of comfort, the assessment of mood states should be suggested to be a fruitful approach.

Up to now different ratings are suggested, but there are only few data, and only for specific applications investigations are available on whether ratings of Likert scales [13], Likert-like scales (numbered labels or quantitative symbols), and visual analog scales (VAS) are comparable [14 - 17]. It remains unclear if the results of the comparison of various types of scales can be generalised [18] and in particular, if the results can be applied in the field of assessing environmental conditions and comfort.

To assess the subjective aspects of environmental circumstances, besides open questions, quantitative methods with a predefined answering format are widely used. This may vary from a yes/no format to Likert scales or Likert-like scales, typically offering three to nine (most times four, five, six, or seven) labelled strengths, to rate the experienced intensity or the believed probability of an item in relation to a question or statement. Whereas in Likert scales, all levels of the items (or the scale) are labelled by a verbal description, Likert-like items (scales) often display numbers representing the extent of the dimension in question, defined by the anchors on both ends of the item (scale). There are some advantages and disadvantages of an item (or a scale) with numbered levels. The advantage is that no assumptions of equidistance between the labels are necessary as it is the case in labelled scales. This is important in particular for the intended subsequent quantitative statistical analysis and also if a score on a scale is calculated by summing up items. For scales with verbal labels, Rohrmann [19] suggests labels with respect to equidistance. A disadvantage of Likert-like scales - which can also be seen as an advantage - is the fact that some persons have problems in quantifying the subjective experience in numbers $(1,2,3,4)$, but would rather prefer to tick pre-defined quantities (e.g. not at all, a little, rather, very much) as shown by Laeroven [20]. This argument is even more appropriate for the VAS. The VAS is a line (often $100 \mathrm{~mm}$ long) with labelled endpoints on which persons are asked to indicate their experienced intensity by placing a mark between the endpoints of the scale. Especially this scale needs an extensive instruction, particularly if persons are naïve to rating scales. In addition to the labelled or numbered endpoints, the VAS may also have a mark of the center of the scale indicating the "neutral" position, or just the middle of something as defined by the endpoints; however, such labels may have a certain impact on the response to the scale [21].

As a complementary method to questionnaires to assess comfort or mood, physiological measurements were suggested to assess the response related to environmental variations [3]. In particular, sympathetic activation and parasympathetic activation are suggested to be objectively measured "on-line" during specific expositions [22] by heart rate variability (HRV). HRV is based on the analysis of normal-to-normal beats of the electrocardiogram and can be quantified in the time domain and the frequency domain [23 - 25]. One parameter of the HRV, namely the high frequency (HF) in the range $0.15 \mathrm{~Hz}-0.40 \mathrm{~Hz}$, is generally considered as an indication of vagal activity, thus reflecting parasympathetic activation [23]. There are numerous works on the meaning of the low frequency (LF; $0.04 \mathrm{~Hz}-0.15$ $\mathrm{Hz}$ ) of the HRV, which is considered to be a mixture of sympathetic and parasympathetic activation [23, 25, 26]. For the very low frequency (VLF; $0.0033 \mathrm{~Hz}-0.04 \mathrm{~Hz}$ ) of the HRV, the origin is not fully understood yet, but besides slow body regulations, also a hormonal contribution, in particular with cortisol, is discussed [27]. 
Due to the lack of a direct comparison of Likert scales, Likert-like scales, and VAS scales of comfort and of mood states, the impact of scale format on usefulness and appropriateness in relation to specific environmental conditions and cardiovascular characteristics was investigated. It was expected that activation-related scales are associated with physiological measures of cardiovascular response and that overall comfort scales and other dimensions of ratings of mood states would give complementary information on the impact of environmental conditions.

\section{METHOD}

\subsection{Participants}

There were forty-five students (34 females) from the University of Vienna and the Medical University of Vienna with a mean age of 25 years $(\mathrm{SD}=3.83)$, ranging from 21 to 41 years. The study was conducted in accordance with the Declaration of Helsinki and approved by the local institution. Participants gave written consent and participated in the study voluntarily and unpaid for credit.

\subsection{Design}

The experiment was conducted according to a MANOVA design with 6 repeated conditions: baseline, positive situation, negative situation, boring situation, Touch for Health, and relaxation. The sequence of the experimental conditions was the same for all participants, but the sequence of filling in the questionnaires was counterbalanced across participants and held constant for each participant for all conditions.

\subsection{Experimental Conditions}

The conditions baseline, positive situation, negative situation, and Touch for Health took five minutes each. The conditions, boring situation and relaxation took $10 \mathrm{~min}$ but only the physiological response of the last 5 min was analysed in those conditions. The room was open to daylight from one side, had a temperature of $23.8^{\circ} \mathrm{C}$ with no background noise $(<50 \mathrm{dBA})$. The expositions to the conditions were separated by at least 5 min from finishing the questionnaire of one condition to the beginning of the next condition.

Baseline ("baseline"). In the baseline condition, no extra environmental manipulation was conducted. Participants sat on chairs with armrests in a seminar room in front of the tables arranged in an inverted U-shape and were allowed to talk to each other. After $5 \mathrm{~min}$, the participants were asked to fill in the questionnaires.

Positive situation ("positive"). This condition had the same setting as the baseline but pictures of nature (trees, lakes, waterfalls, mountains, animals) were presented by Power Point, accompanied by a soft rainforest sound. After 5 min presentation time, the participants were asked to fill in the questionnaires, with the presentation on-going.

Negative situation ("negative"). In this condition, 26 emotionally negative pictures from the IAPS [28] with 4 pictures from a dentist at work in between were presented, accompanied by the sounds of a dentist playing drill. After 5 min presentation time, the participants were asked to sit on the table, with dangling feet, and to fill in questionnaires while the presentation continued.

Boring situation ("boring"). To induce boredom, the setting of the baseline was changed in so far that the participants had to sit for 10 min without any conversation or communication, and no kind of stimulation was given.

Touch for Health ("touch"). To induce a certain level of activation, specific exercises from the kinesiological approach were applied, which are based on the assumption that stimulating so-called meridians would change the socalled energy flow [29]. In this experimental condition, participants stood up and (1) tapped the right hand from the left shoulder down to the left hand and back several times and then the same with the left hand on the right arm. (2) Participants rubbed upper and lower lips with one hand as well as their belly button with the other hand; and, finally, (3) they rubbed their ear lobes.

Relaxation ("relaxation"). Based on the technique of progressive muscle relaxation of Jacobson [30], participants had to tense the muscles in the dominant hand and then to relax them. This procedure of changing and pronouncing the change from tension to relaxation was thereafter done with the lower arm, upper arm and shoulder, the other arm, the feet and the face. During this condition and the time of filling in questionnaires, scented candles were burned.

\subsection{Ratings of State Moods (TRIM-S)}

Whereas Trimmel's Index of Trait Moods (TRIM-T) is considered to be a measure of the frequency of experiencing 
four dimensions of moods in general [25], Trimmel's Index of Mood States (TRIM-S) is suggested as a short measure of the intensity of four dimensions of moods in the private and work context at the moment. Reliability analysis of unpublished data $(\mathrm{N}=194)$ of TRIM-S using the 4-point intensity answering format (see below) indicated that the 4 scales of TRIM-S have an acceptable to good reliability [31] as indicated by Cronbach's alpha (CA): relaxation (CA = $0.75)$, motivation $(\mathrm{CA}=0.76)$, good $\operatorname{mood}(\mathrm{CA}=0.84)$ and energy $(\mathrm{CA}=0.86)$.

To investigate the impact of the answering format of the 16 items, three different formats, namely a 4-point Likert scale, a 7-point Likert-like scale, and a VAS were presented. The items had to be scaled as the answers of the statement "At the moment I feel ..." in the 4-point answering format "not at all" (überhaupt nicht), "a little" (ein wenig), "rather" (ziemlich), and "very much" (sehr); in the 7-point answering format the endpoints were anchored with "not at all" (überhaupt nicht) and "very much" (sehr stark) and in addition, the 7 positions were numbered from " 0 " to "6"; and in the VAS, the endpoints were anchored with "not at all" (überhaupt nicht) and "very much" (sehr stark) and in addition with the numbers " 0 " and " 100 " on the $140 \mathrm{~mm}$ scale which was divided in 20 equal segments by small marks (Fig. 1).

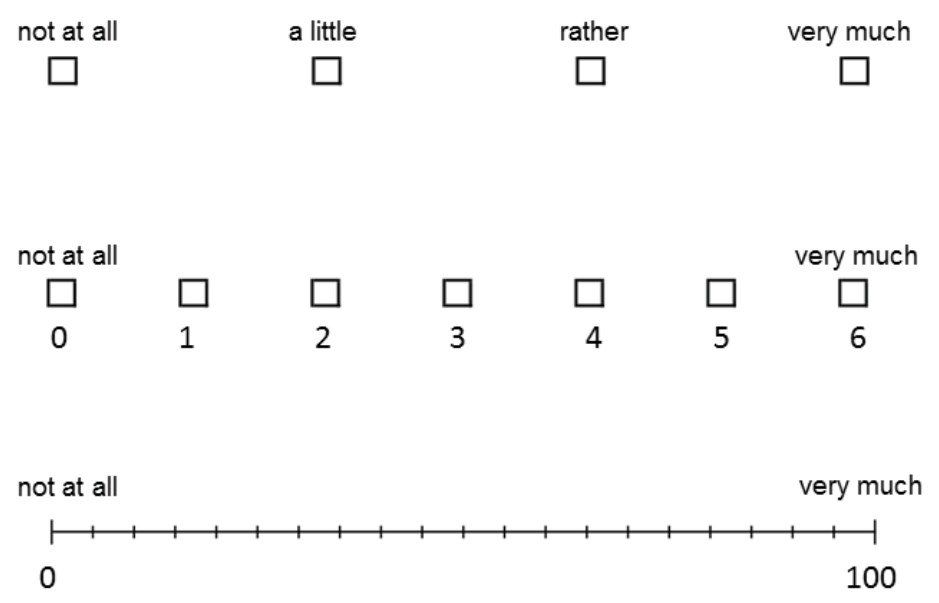

Fig. (1). Answering formats of TRIM-S.

Each of the 4 dimensions of TRIM-S (relaxation, motivation, good mood, energy) were calculated from 4 items, each of the two items of which were positive and two items were negative - which had to be coded reversely ([-], i.e. in the case of the 4-point scale by calculating 5 minus the score; in the case of coding from 1-4). "Relaxation" (Entspannung) with the items relaxed (entspannt), calm (gelassen), [-]nervous (nervös), and [-]restless (unruhig). "Motivation" (Motivation) with the items willing to show effort (anstrengungsbereit), willing to perform (leistungsmotiviert), [-]bored (gelangweilt), [-]indifferent (gleichgültig). "Good mood” (Gute Stimmung) with the items good mood (gute Stimmung), cheerful (heiter), [-]depressed (deprimiert), [-]downhearted (niedergeschlagen). "Energy" (Energie) with the items fresh (frisch), energized (energiegeladen), [-]tired (müde), [-]sleepy (schläfrig). See Appendix A for the questionnaire and the sequence of the items with the 4-point answering format.

\subsection{Ratings of Overall Comfort}

As in the present experiment, specific dimensions of environmental conditions were not investigated adequately (with the exception of sitting in the negative situation condition - to some extent) only overall aspects of comfort were related to the experimental conditions. Experience in the commercial context [11] indicates that short questionnaires, or even single item scales are preferred. Therefore four single item scales were compared: two 4-point scales, one assuming comfort as a positive experience and one assuming comfort as the absence of discomfort (see Fig. (2) for the used labels), one 7-point scale Fig. (2), and one VAS Fig. (2) all with the introducing statement: "At the moment, the conditions in general are ..." (Im Moment sind mir die Bedingungen insgesamt ...).

\subsection{Heart Rate and Heart Rate Variability}

For the whole duration of the experiment, the electrocardiogram (ECG) was recorded from a modified Lead II configuration by portable Holter ECG recorders (Medilog AR12 from Schiller-Engineering, Graz, Austria, http://schiller.at) with a digitalisation rate of $4 \mathrm{kHz}$ and analysed by the program Medilog Darwin (http://schiller.at). 
After visual inspection of the signal, 5 min epochs of the experimental conditions were analysed. Heart rate (HR) and parameters of HRV like relative $(\%)$ power of $\mathrm{HF}(0.15 \mathrm{~Hz}-0.40 \mathrm{~Hz}), \mathrm{LF}(0.04 \mathrm{~Hz}-0.15 \mathrm{~Hz})$, and VLF $(0.0033 \mathrm{~Hz}-$ $0.04 \mathrm{~Hz})$ as well as the logarithmic score of LF/HF (log LF/HF) were analysed for normal-to-normal (NN) beat intervals.

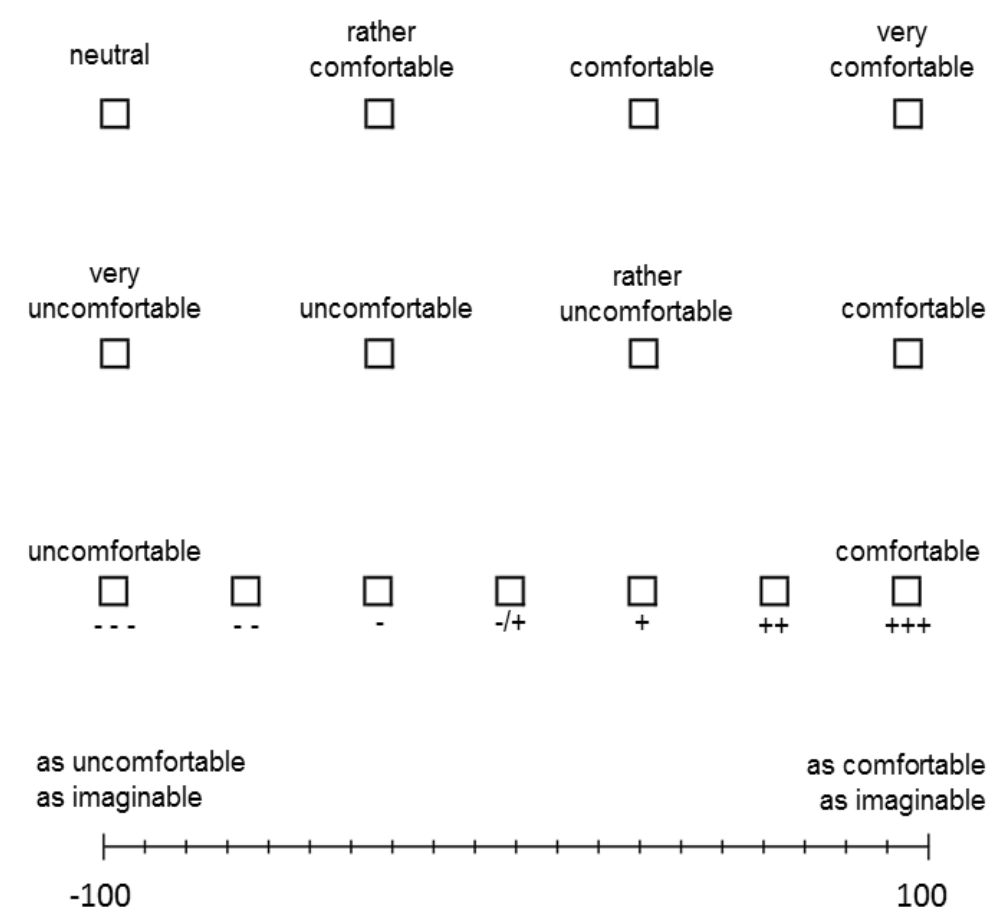

Fig. (2). Answering formats of the overall comfort ratings.

\subsection{Procedure}

Data collection was done in two sessions with 23 and 22 participants simultaneously. After arriving at the facility, participants were instructed that they would be exposed to different environmental conditions and that their psychological as well as their physiological responses were the subject of the investigation. After signing written consent, they were administered the ECG Holter recording equipment, sat down and were asked to fill in a questionnaire on demographic information and personal background information. After the experiment, the participants were debriefed.

\subsection{Analysis}

Statistical analysis was performed by multivariate general linear models of Statistica 10.0 (StatSoft, Inc., 2011; www.statsoft.com). This approach is robust against violations of the assumptions of compound symmetry and sphericity in repeated measurement designs (StatSoft, Inc., 2011; www.statsoft.com). Statistically significant effects $(\mathrm{p}<0.05)$ were further interpreted by mean values and $95 \%$ confidence intervals $(\mathrm{CI})$ according to the so-called Cousineau-Morey method (32). Cousineau and O'Brien [32] suggested "that if 95\% CIs are drawn, the means are not different at a decision threshold of .05 if the $\mathrm{CI}$ in one condition contains the mean of another condition; conversely, the means are different if the CI in one condition does not contain the mean of another condition" (p. 1151).

\section{RESULTS}

\subsection{Trimmel's Index of Mood States (TRIM-S)}

Four-point scale. Two-way multivariate analysis for repeated measurements (6 Conditions X 4 Scales) indicated the main effects for condition $\left(F(5,40)=3.94, p=0.005, \eta_{p}{ }^{2}=0.12\right)$ and scale $\left(F(3,42)=37.86, p<0.001, \eta_{p}{ }^{2}=0.45\right)$, as well as for their interaction $\left(\mathrm{F}(15,30)=2.42, \mathrm{p}=0.019, \eta_{\mathrm{p}}{ }^{2}=0.11\right)$. Mean values and $95 \% \mathrm{CI}$ are presented in (Fig. 3).

Seven-point scale. Two-way multivariate analysis for repeated measurements (6 Conditions X 4 Scales) indicated 
the main effects for condition $\left(\mathrm{F}(5,40)=5.81, \mathrm{p}<0.001, \eta_{\mathrm{p}}{ }^{2}=0.15\right)$ and scale $\left(\mathrm{F}(3,42)=33.49, \mathrm{p}<0.001, \eta_{\mathrm{p}}{ }^{2}=0.45\right)$, as well as for their interaction $\left(\mathrm{F}(15,30)=4.23, \mathrm{p}<0.001, \eta_{\mathrm{p}}{ }^{2}=0.11\right)$. Mean values and $95 \% \mathrm{CI}$ are presented in (Fig. 4).

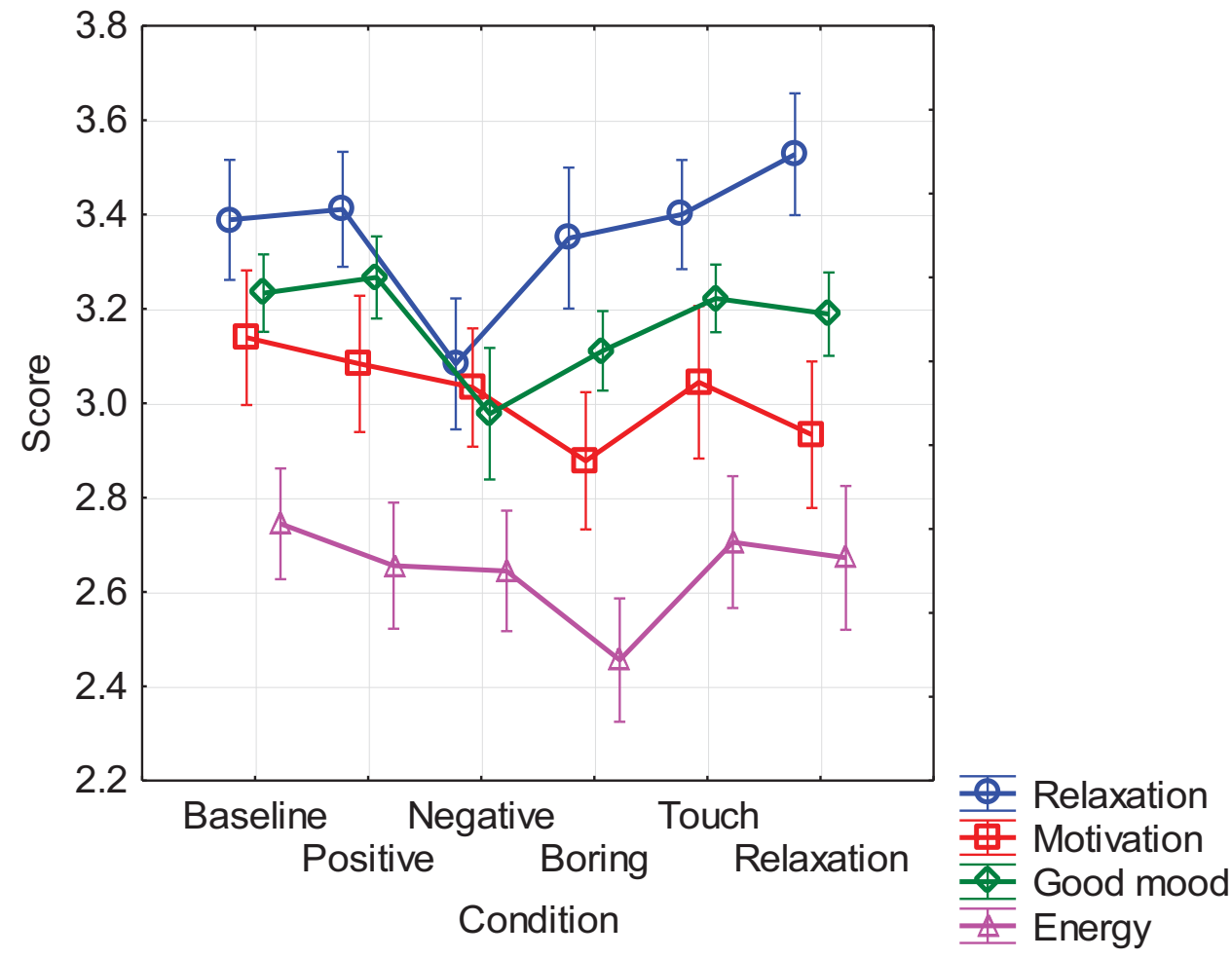

Fig. (3). Mean values and 95\% CI of ratings of state moods (TRIM-S) on the 4-point scale by condition.

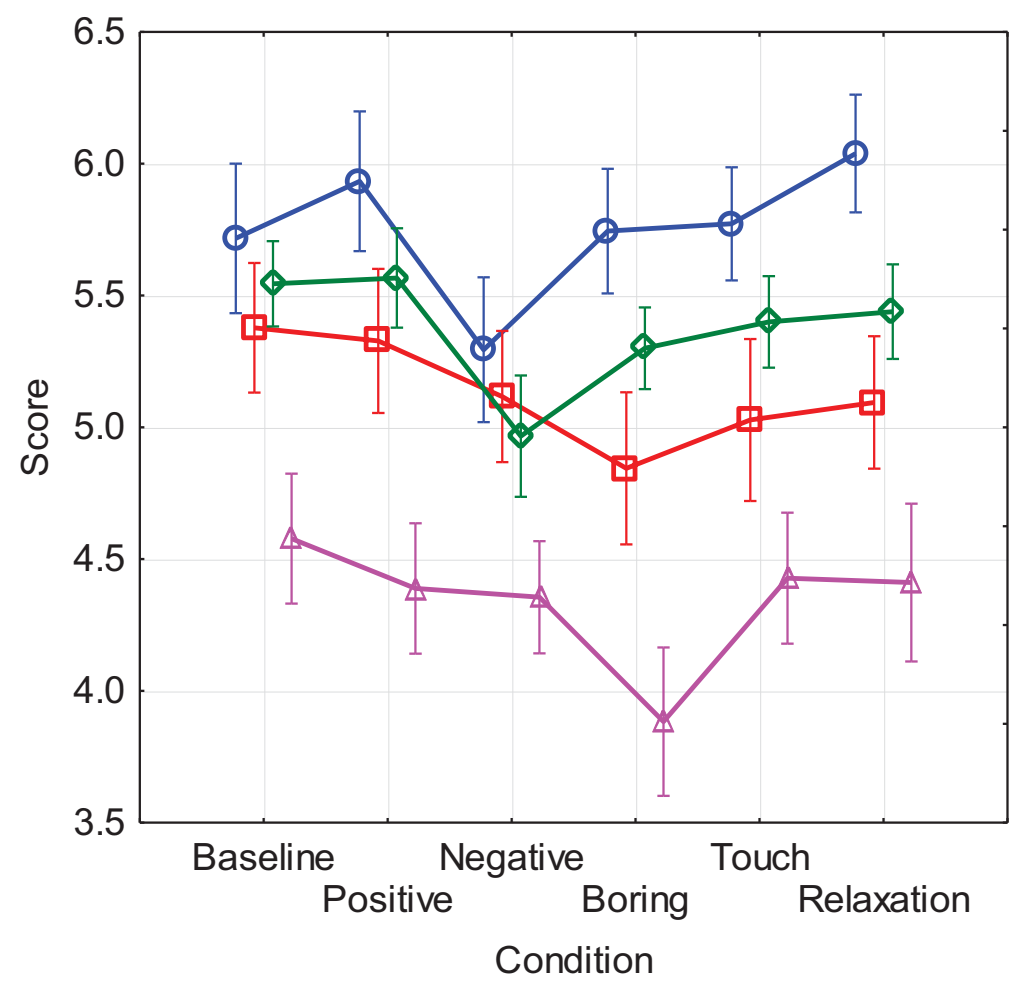

Fig. (4). Mean values and 95\% CI of ratings of state moods (TRIM-S) on the 7-point scale by condition. 
$V A S$-scale. Two-way multivariate analysis for repeated measurements (6 Conditions X 4 Scales) indicated the main effects for condition $\left(\mathrm{F}(5,40)=5.09, \mathrm{p}=0.001, \eta_{\mathrm{p}}{ }^{2}=0.13\right)$ and scale $\left(\mathrm{F}(3,42)=76.25, \mathrm{p}<0.001, \eta_{\mathrm{p}}{ }^{2}=0.57\right)$, as well as for their interaction $\left(\mathrm{F}(15,30)=2.94, \mathrm{p}=0.006, \eta_{\mathrm{p}}{ }^{2}=0.12\right)$. Mean values and $95 \% \mathrm{CI}$ are presented in (Fig. 5).

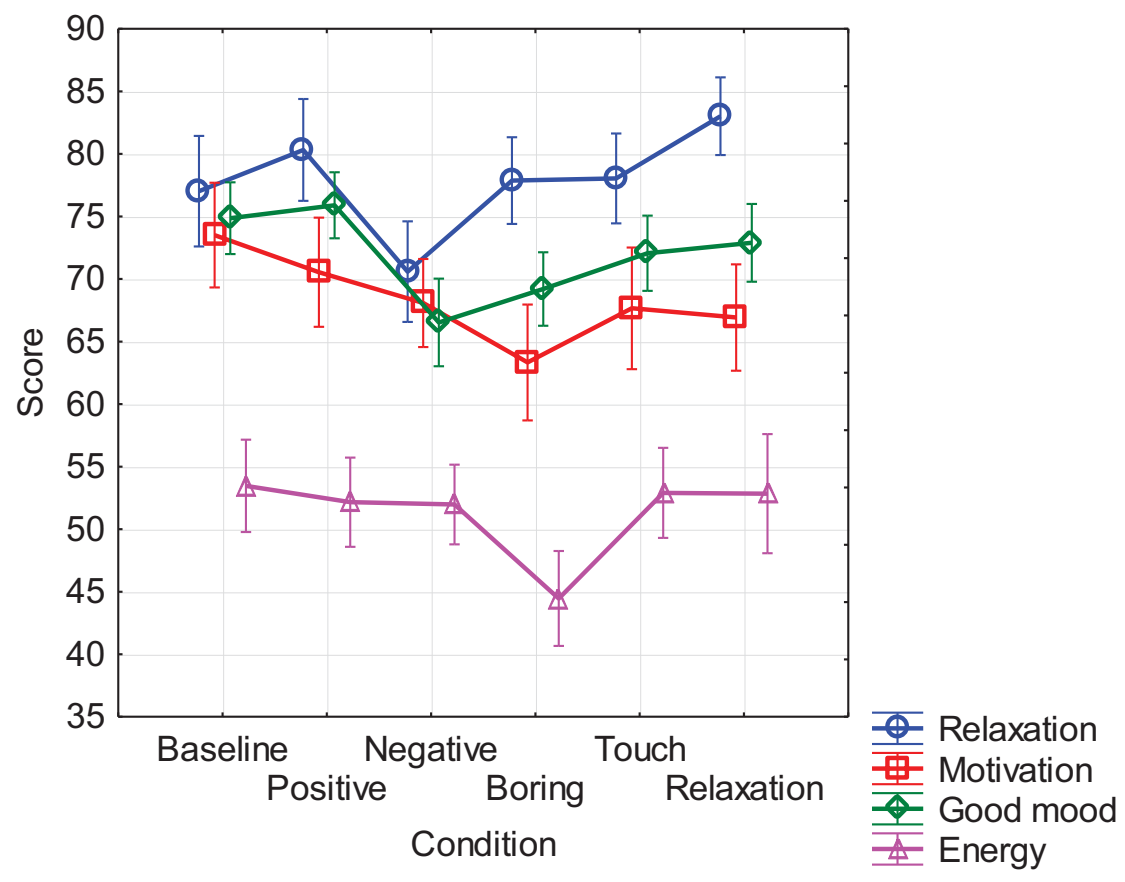

Fig. (5). Mean values and 95\% CI of ratings of state moods (TRIM-S) on the VAS scale by condition.

\subsection{Ratings of Comfort}

Four-point scale on comfort. Multivariate analysis for repeated measurements indicated a statistically significant effect for condition $\left(F(5,40)=35.35, \mathrm{p}<0.001, \eta_{\mathrm{p}}{ }^{2}=0.37\right)$. Mean values with $95 \% \mathrm{CI}$ are presented in (Fig. 6).

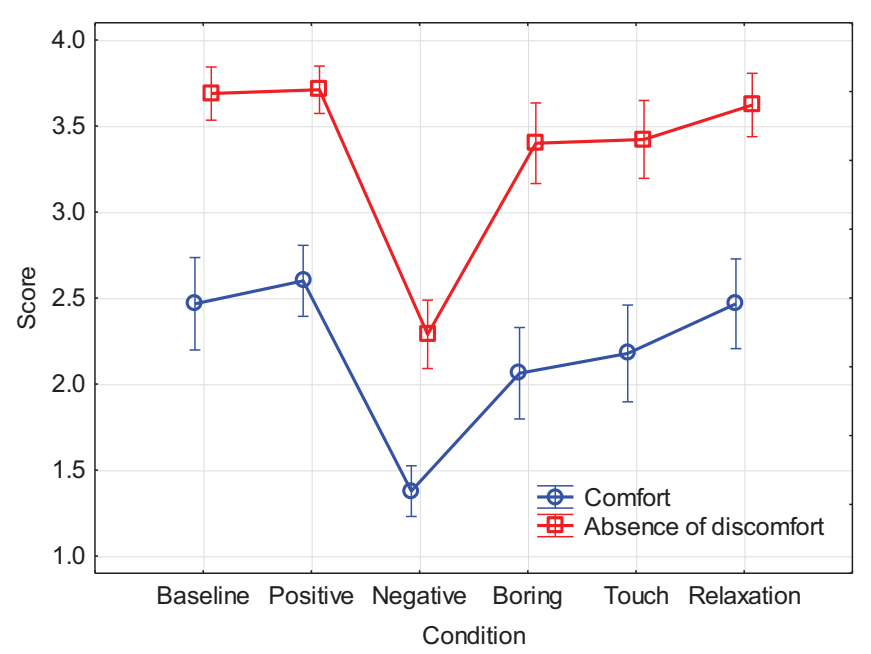

Fig. (6). Mean values and 95\% CI of ratings of comfort on the 4-point scales by condition.

Four-point scale on absence of discomfort. Multivariate analysis for repeated measurements indicated a statistically significant effect for condition $\left(\mathrm{F}(5,40)=34.48, \mathrm{p}<0.001, \eta_{\mathrm{p}}{ }^{2}=0.53\right)$. Mean values with $95 \% \mathrm{CI}$ are presented in (Fig. 6).

Results showed generally higher scores for the ratings of absence of discomfort compared to ratings of comfort, but 
the effect of condition showed a comparable pattern on both scales. Comparing both the scales, only one difference in the ratings of comfort appeared, namely in the "absence of discomfort rating" the difference between the boring condition and the relaxation condition did not appear contrary to the "comfort rating".

Seven-point scale on comfort. Multivariate analysis for repeated measurements indicated a statistically significant effect for condition $\left(\mathrm{F}(5,40)=34.21, \mathrm{p}<0.001, \eta_{\mathrm{p}}{ }^{2}=0.53\right)$. Mean values with $95 \% \mathrm{CI}$ are presented in Fig. (7). As for the ratings on the 4-point scale, no differences appeared between baseline, positive, and relaxation condition and like in the rating of comfort on the 4-point scale, the relaxation condition was experienced as being more comfortable than the boredom.

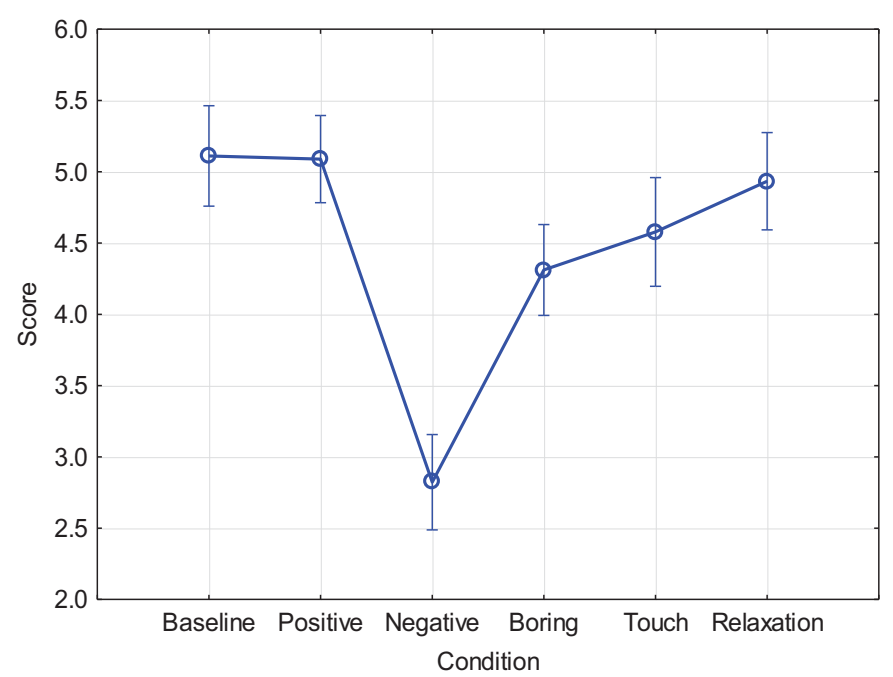

Fig. (7). Mean values and 95\% CI of ratings of comfort on the 7-point scale by condition.

VAS scale on comfort. Multivariate analysis for repeated measurements indicated a statistically significant effect for condition $\left(\mathrm{F}(5,40)=20.03, \mathrm{p}<0.001, \eta_{\mathrm{p}}{ }^{2}=0.39\right)$. Mean values with 95\% CI are presented in Fig. (8). Like in the ratings on the 4-point and the 7-point scales, no differences appeared between baseline, positive, relaxation, and touch condition. Furthermore, like in the ratings of comfort on the 4-point scale and the 7-point scale, the relaxation condition was experienced as being more comfortable than the boredom.

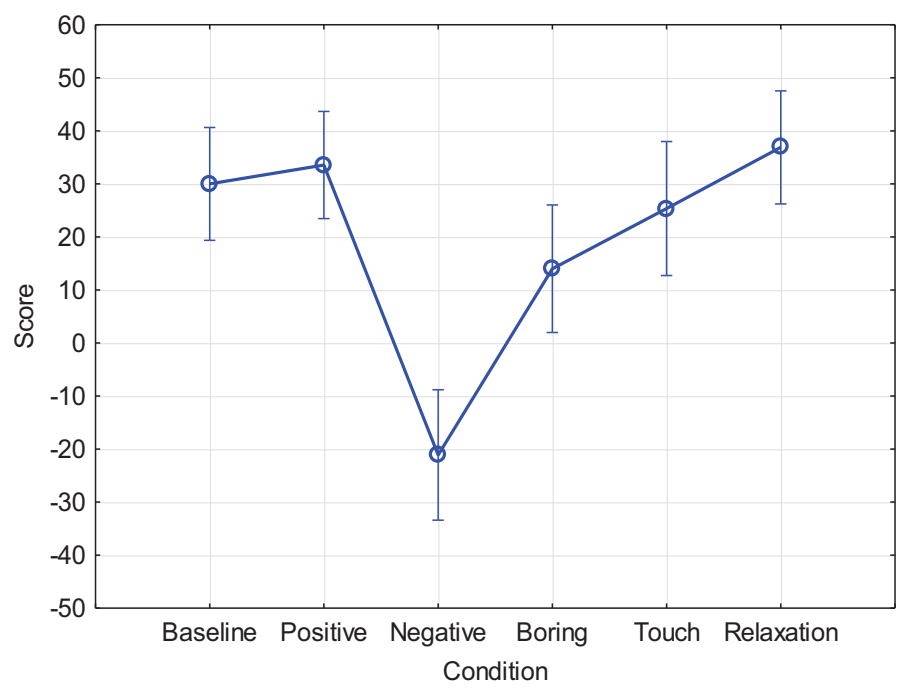

Fig. (8). Mean values and 95\% CI of ratings of comfort on the VAS-scale by condition. 


\subsection{Heart Rate and Heart Rate Variability}

Heart rate $(H R)$. Multivariate analysis for repeated measurements indicated a statistically significant effect for condition $\left(\mathrm{F}(5,40)=50.77, \mathrm{p}<0.001, \eta_{\mathrm{p}}{ }^{2}=0.50\right)$. Mean values with 95\% CI are presented in Fig. (9). Highest HR was observed in the touch condition with the lowest HR in the boring condition whereas CI indicated no differences between positive, negative, boring, and relaxation condition.

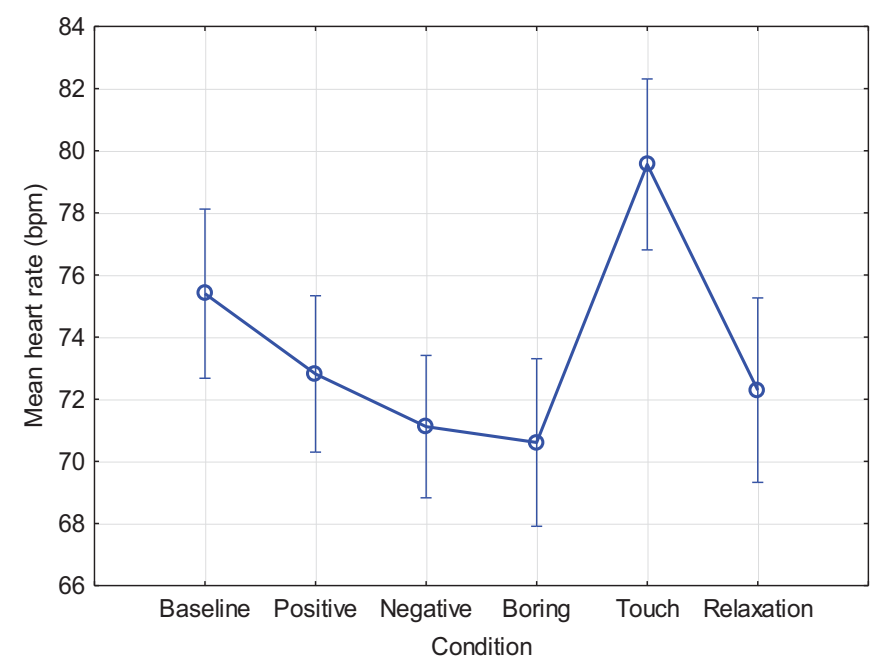

Fig. (9). Mean values and 95\% CI of mean heart rate by condition.

Relative power (\%) in the frequency bands $V L F, L F$, and $H F$ of $H R V$. Two-way multivariate analysis for repeated measurements (6 Conditions X 3 Bands) indicated the main effects for condition $\left(F(5,38)=2.72, p<0.05, \eta_{\mathrm{p}}{ }^{2}=0.03\right)$ and band $\left(\mathrm{F}(2,41)=184.03, \mathrm{p}<0.001, \eta_{\mathrm{p}}{ }^{2}=0.75\right)$, as well as for their interaction $\left(\mathrm{F}(10,33)=3.11, \mathrm{p}<0.01, \eta_{\mathrm{p}}{ }^{2}=0.09\right)$. Mean values and 95\% CI are presented in Fig. (10). Relative power in all 3 frequency bands showed condition-related differences. High values of $\mathrm{HF} \%$ were observed for the boring and relaxation condition and the lowest value appeared in the touch condition. For LF\%, the lowest value was observed in the touch condition, which appeared lower than the value in all other conditions except the positive condition. For VLF\%, high values were observed in the touch condition but also in the positive condition, whereas for baseline and boring low values were observed.

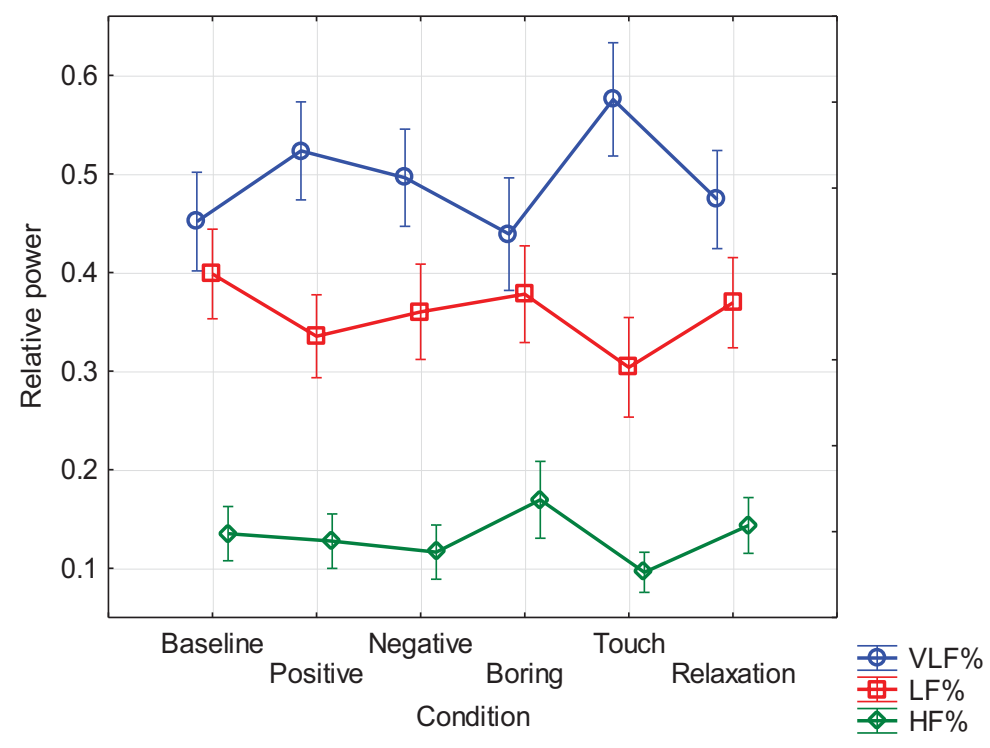

Fig. (10). Mean values and 95\% CI of relative power (\%) of VLF, LF, and HF by condition. 
$\log L F / H F$ of $H R V$. Multivariate analysis for repeated measurements indicated a statistically significant effect for condition $\left(F(5,38)=2.70, p<0.05, \eta_{p}{ }^{2}=0.06\right)$. Mean values with 95\% CI are presented in Fig. (11). Log LF/HF showed lower values in boring and relaxation conditions compared to baseline, negative, and touch conditions. In addition, higher values were observed in the negative condition compared to the positive condition.

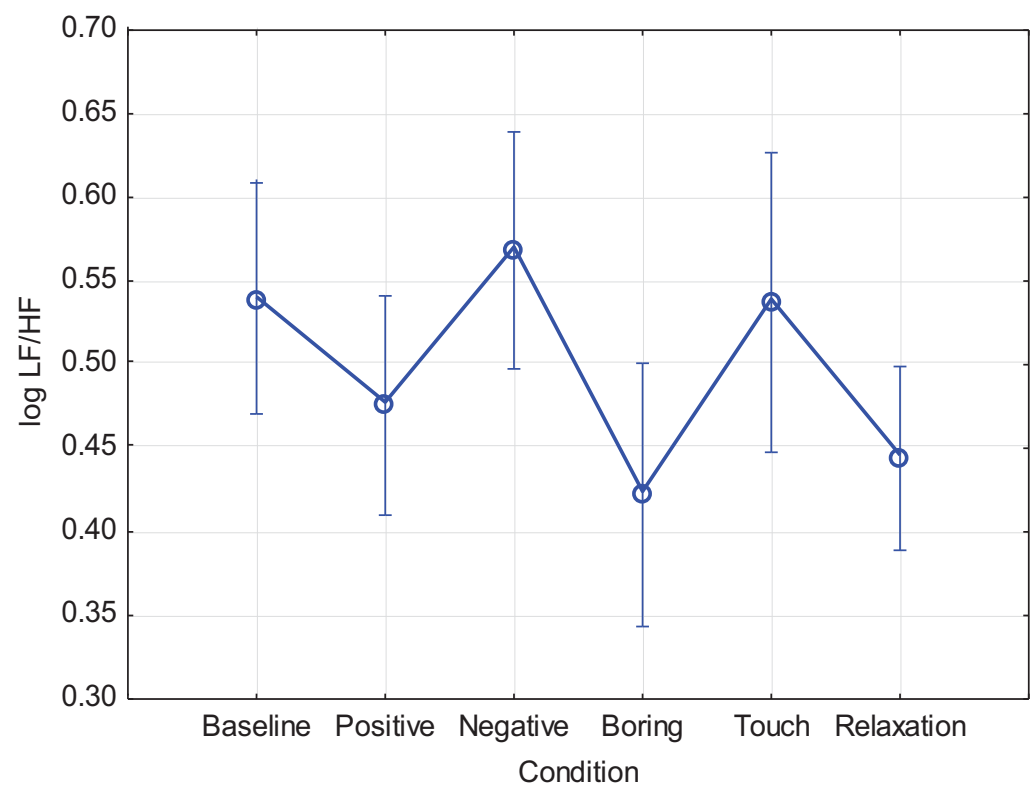

Fig. (11). Mean values and 95\% CI of $\log \mathrm{LF} / \mathrm{HF}$ of HRV by condition.

\section{DISCUSSION}

\subsection{Every-day Mood States}

Ratings of every-day mood states by Trimmel's Index of Moods States (TRIM-S) showed that conditions lead to a different perception in at least one of the four dimensions. Moreover, in nearly all - with the exception of the positive condition -, in each dimension, a difference to the baseline was observed. As a main result, that pattern was observed independent of the answering format, i.e. four-point scale, seven-point scale, and VAS.

The specificity of the four every-day mood dimensions in TRIM-S was determined by the comparison of the conditions, for which an answering format with independent pattern appeared. Scores of the dimension "relaxation" were highest for the condition relaxation and lowest for the negative condition in all answering formats. The dimension "motivation" scored the highest in the baseline and lowest in the condition boring, again independent of the answering format. For "good mood", the highest scores were observed in the positive condition and lowest scores were observed in the negative condition, in all the answering formats. The rating of "energy" showed the lowest scores for the boring condition and highest scores for baseline and the second highest score, not differing from baseline, in the touch condition - again in all the answering formats, thus confirming the dimensional structure of mood as proposed earlier [25].

Although ratings of mood by different answering formats of TRIM-S are not identical, it appears that the investigated answering formats did not differ in sensitivity with respect to the investigated environmental conditions.

\subsection{Comfort}

Ratings of overall comfort were plausible in relation to conditions and showed no remarkable differences in the three answering formats.

In addition to the comparison of the answering format, the concept of "comfort" was compared with the concept of "absence of discomfort" - which was found to be a fruitful distinction at least by identifying relevant factors of comfort in sitting [8] - in the four-point scale only. Results are comparable in relation to condition, however, the concept of 
"absence of discomfort" showed generally high scores, which may, theoretically, easily lead to a ceiling effect and is therefore less recommended.

\subsection{Heart Rate (HR) and Heart Rate Variability (HRV)}

HR was the lowest in the boring condition and highest in the touch condition with a mean difference of $9 \mathrm{bpm}$. In particular, the accelerated HR in the touch condition, which was also $4 \mathrm{bpm}$ higher than in the baseline, indicates that by the technique of "Touch for Health" [29] a remarkable activation [33] of the cardiovascular system could easily be provoked in a short time, at least for a short duration.

From the frequency bands of HRV, HF is the best understood as an indication of parasympathetic activation [23]. This is reflected by the present investigation, as the lowest values for HF\% were found in the touch condition and the highest values in the boring condition, and high values were also observed in the relaxation condition and in baseline. The response to experimental conditions in $\mathrm{LF} \%$ is essentially comparable to that of $\mathrm{HF} \%$, but the experimental effects are more clearly reflected by the inverse response of VLF\%. This is seen in particular in the lower LF\% of the positive condition compared to the baseline, for which the opposite response in VLF\% was observed. This effect, the difference of VLF\% in the positive condition compared to baseline as well as the difference compared to the boring condition indicates a sensitivity of VLF\% to emotional arousal. The sensitivity to the arousal of VLF\% was also obvious by the high value in the touch condition. Thus, VLF seems to be inversely related to LF to some extent, but more sensitive to emotional positive cardiovascular activation.

The contrary sensitivity, namely for emotional negative stimulation, or at least for task-related cardiovascular activation, was observed for LF/HF. Log LF/HF showed the highest value for the negative condition, which was higher than in the positive condition, the boring condition and the relaxation condition. Thus, this unequal response pattern indicates some sensitivity for the emotional negative activation, or at least for task-related activation, as comparable values were also observed for baseline and touch condition.

\subsection{Ratings by TRIM-S and Cardiovascular Response}

Ratings of high relaxation by TRIM-S were accompanied by low HR, relatively high values of HF\%, and by low scores of log LF/HF. But, contrary to physiological variables, only ratings of mood - in particular in the four-point scale and in the VAS scale - showed the highest values for the relaxation condition, which, however, are only marginally different to the good mood condition.

Ratings of high motivation by TRIM-S were found predominately in the baseline and the good mood condition, independent of the type of scale. This is accompanied by ratings of high comfort in both conditions; however, such a high comfort was also rated in the relaxation condition - contrary to motivation, for which at least a difference to baseline was observed. None of the cardiovascular parameters showed a comparable pattern, indicating that such a psychological construct seems not to relate to the cardiovascular activity in a direct manner suggesting to display additional information [34]. However, one may speculate that a moderate HR - not too low and not too high - could be an accompanying cardiovascular sign of motivation. This is, to some extent, indicated by the present data, because for low HR (negative and boring conditions) and high HR (Touch for Health condition), ratings of motivation were lower than for the moderate HR in baseline. Such a relationship was already proposed by pioneers of activation theory 100 years ago onwards $[33,35,36]$.

Ratings of good mood by TRIM-S were particularly high in the positive condition compared to the negative condition and this was also found for the ratings of comfort. In cardiovascular response, this was only reflected by the $\log \mathrm{LF} / \mathrm{HF}$ with a low value in the positive condition, indicating a relatively high parasympathetic activity, and a high value in the negative condition, indicating a relatively low parasympathetic activity. However, as this score is not different from the $\log \mathrm{LF} / \mathrm{HF}$ in the boring condition and in the relaxation condition, none of the investigated parameters of the cardiovascular response can be identified to reflect the psychological construct of good mood.

Ratings of energy by TRIM-S were particularly low in the boring condition compared to all other conditions, independent of the scale format. Low values for the boring condition were also observed in all scales of comfort, for which, however, lower scores were observed in the negative condition. The boring condition provoked the lowest HR, however, HR was not different to negative condition, positive condition, nor relaxation condition, thus indicating that the rating of energy by TRIM-S is related to HR but is more sensitive than HR measures. Also HF\% was highest in the boring condition, indicating that parasympathetic activity is inversely related to the psychological concept of energy, 
but high values of $\mathrm{HF} \%$ were also observed for the relaxation condition. A comparable pattern is also found in log $\mathrm{LF} / \mathrm{HF}$ - low values of $\log \mathrm{LF} / \mathrm{HF}$ in the boring condition, but also in relaxation condition and positive condition -, thus, indicating that the rating of energy by TRIM-S seems to be more sensitive than HRV measures, at least for the investigated conditions.

\subsection{Limitations of the Study}

Reported effects of environmental conditions on subjective experience and on the cardiovascular system are the result of investigating short term periods of $5 \mathrm{~min}$ intervals, which are also the shortest possible periods to analyse the power of VLF [23]. That means that longer periods of specific environmental conditions may be associated with a different response pattern because of adaptation, coping with the situation, sensitisation to specific aspects, etc. In this study, no personal aspects such as personality, experience with specific environmental conditions, experience with relaxation techniques, etc. were considered as possible moderator variables.

Another limitation of the study comes from the design, as the sequence of the experimental conditions was not balanced across the test participants and test participant $\mathrm{s}$ were in a more highly motivated and more positive mood state at the beginning of the experiment. Of course a fully balanced design would give a more accurate picture of the effect of the conditions on the subjective and physiological response. However, due to position effects and sequence effects, a greater sample - unusual in psychophysiological experiments - would have been appropriate for such a design. Moreover, the present experiment was conceptualised to compare different answering formats and their relation to the physiological response. Therefore, the balanced order of filling in the rating scales across subjects seems to be sufficient to compare the properties of the scales and their interaction with the physiological response.

\subsection{Concluding Discussion}

To sum up, ratings and cardiovascular response of the investigated experimental conditions are not identical but complementary. Thus, to assess the impact of environmental or ergonomic characteristics on interaction with the intention or the task of an engaged person, it is suggested to consider both response systems, namely the subjective (emotional, motivational, cognitive) experience and the physiological response. In fact, to get a full picture of the environmental or ergonomic impact on a person, the third response system, namely the behavioral system - often assessed by characteristics in human performance - as suggested by the tripartite model [34], should be considered as well; however, behavior was not in the focus of this investigation.

For mood ratings by TRIM-S as well as for ratings of overall comfort, the investigated scales of labelled four-point Likert scale, seven-point Likert-like scales, and VAS scales did not display remarkable differences in response to five artificial environmental interactions and the baseline. Thus, additional aspects in the application of those questionnaires, like the experience of the target sample in filling the questionnaires - because persons inexperienced in ratings are not enthusiastic with the VAS but may prefer Likert scales, in particular those with 3 to 5 labels - should be considered. This may be based on limitations of human information processing. Although the upper limitations of information processing are considered to be 7 plus/minus 2 elements [37], a central memory store limited to 3 to 5 meaningful items is suggested by Cowan [38]. Thus, ratings with more than 3 to 5 labels may be associated with higher mental effort, in particular for persons not highly experienced in ratings or in children [39]. This point of view is also supported by a higher reliability of 5 response alternatives compared to 7 response alternatives [40]. Another issue in considering the answering format is based on aspects of analysis [12]. In case of the intention to quantify the response on Likert scales, it is necessary that there is no violation of the equidistance of the used labels [19] and it was also suggested, at least for the field of stress and health related assessments, that the absolute value of scores of Likert scales and of VAS may differ and therefore scales are comparable but not interchangeable [16]. It is recommended that such aspects together with ecological considerations may guide users in the decision which type of scale should be chosen in such instruments.

Physiological measures of cardiovascular response give an objective on-line picture of response, in particular of activation processes [41, 42]. The response patterns of every-day mood states gathered by TRIM-S and physiological parameters indicate that (1) the activation-related dimensions of relaxation and energy are associated with cardiovascular activity and that (2) the psychological concepts of motivation and good mood are also sensitive to environmental conditions but not directly covered by the investigated physiological parameters. Thus, psychological concepts like motivation, good mood, and comfort seem to be more sensitively gathered by questionnaires as indicated by the results on TRIM-S and by the ratings of overall comfort. 
Appendix A. TRIM-S questionnaire with the 4-point answering format.

At the MOMENT I feel...

\begin{tabular}{lcccc}
\hline & not at all & a little & rather & very much \\
\hline tired & $\square$ & $\square$ & $\square$ & $\square$ \\
\hline relaxed & $\square$ & $\square$ & $\square$ & $\square$ \\
\hline willing to perform & $\square$ & $\square$ & $\square$ & $\square$ \\
\hline sleepy & $\square$ & $\square$ & $\square$ & $\square$ \\
\hline nervous & $\square$ & $\square$ & $\square$ & $\square$ \\
\hline bored & $\square$ & $\square$ & $\square$ & $\square$ \\
\hline restless & $\square$ & $\square$ & $\square$ & $\square$ \\
\hline depressed & $\square$ & $\square$ & $\square$ & $\square$ \\
\hline downhearted & $\square$ & $\square$ & $\square$ & $\square$ \\
\hline cheerful & $\square$ & $\square$ & $\square$ & $\square$ \\
\hline indifferent & $\square$ & $\square$ & $\square$ & $\square$ \\
\hline energetic & $\square$ & $\square$ & $\square$ & $\square$ \\
\hline willing to show effort & $\square$ & $\square$ & $\square$ & $\square$ \\
\hline in a good mood & $\square$ & $\square$ & $\square$ & $\square$ \\
\hline fresh & $\square$ & $\square$ & $\square$ & $\square$ \\
\hline calm & $\square$ & $\square$ & $\square$ \\
\hline
\end{tabular}




\section{HUMAN AND ANIMAL RIGHTS}

No Animals/Humans were used for studies that are base of this research.

\section{CONSENT FOR PUBLICATION}

Not applicable.

\section{CONFLICT OF INTEREST}

The authors declare no conflict of interest, financial or otherwise.

\section{ACKNOWLEDGEMENTS}

The authors want to thank S. Maurer, C. Pristernik, and E. Wartak for helping in data collection and G. Langer for assisting in preparing the manuscript.

\section{REFERENCES}

[1] Trimmel M, Atzlsdorfer J, Tupy N, Trimmel K. Effects of low intensity noise from aircraft or from neighbourhood on cognitive learning and electrophysiological stress responses. Int J Hyg Environ Health 2012; 215(6): 547-54. [http://dx.doi.org/10.1016/j.ijheh.2011.12.007] [PMID: 22257928]

[2] Trimmel M, Poelzl G. Impact of background noise on reaction time and brain DC potential changes of VDT-based spatial attention. Ergonomics 2006; 49(2): 202-8.

[http://dx.doi.org/10.1080/00140130500434986] [PMID: 16484145]

[3] Trimmel M. Environmental conditions and psychophysiological response of pilots and flight attendants in commercial long-haul flights. Ergonomics Open Journal 2008; 1: 67-78. [http://dx.doi.org/10.2174/1875934300801010067]

[4] Trimmel K, Schätzer J, Trimmel M. Acoustic noise alters selective attention processes as indicated by direct current (DC) brain potential changes. Int J Environ Res Public Health 2014; 11(10): 9938-53. [http://dx.doi.org/10.3390/ijerph111009938] [PMID: 25264675]

[5] Trimmel M, Burger M, Langer G, Trimmel K. Treatment of fear of flying: Behavioral, subjective, and cardiovascular effects. Aviat Space Environ Med 2014; 85(5): 550-62.

[http://dx.doi.org/10.3357/ASEM.3821.2014] [PMID: 24834570]

[6] Slater K. Human Comfort. Springfield, Ill.: C. C. Thomas 1985.

[7] Vink P, Hallbeck S. Editorial: Comfort and discomfort studies demonstrate the need for a new model. Appl Ergon 2012; $43(2)$ : 271-6. [http://dx.doi.org/10.1016/j.apergo.2011.06.001] [PMID: 21724175]

[8] Zhang L, Helander MG, Drury CG. Identifying factors of comfort and discomfort in sitting. Hum Factors 1996; 38(3): 377-89. [http://dx.doi.org/10.1518/001872096778701962]

[9] ANSI/ASHRAE . Thermal Environmental Conditions for Human Occupancy. Atlanta, NE: ASHRAE 2014.

[10] Fanger PO. Thermal Comfort. New York: McGraw Hill 1972.

[11] Grün G, Trimmel M, Holm A. Low humidity in the aircraft cabin environment and its impact on well-being - Results from a laboratory study. Build Environ 2012; 47(4): 23-31.

[http://dx.doi.org/10.1016/j.buildenv.2011.05.004]

[12] Baumann I, Trimmel M. Distribution of subjective assessments in a controlled aircraft environment. Aerosp Sci Technol 2013; 25(1): 93-101. [http://dx.doi.org/10.1016/j.ast.2011.12.012]

[13] Likert R. A technique for the measurement of attitudes 1932.

[14] Bolognese JA, Schnitzer TJ, Ehrich EW. Response relationship of VAS and Likert scales in osteoarthritis efficacy measurement. Osteoarthritis Cartilage 2003; 11(7): 499-507. [http://dx.doi.org/10.1016/S1063-4584(03)00082-7] [PMID: 12814613]

[15] Giannini SP, Latorre MdoR, Ferreira LP. Condition of Vocal Production-Teacher questionnaire: Comparison of responses on Likert scale and visual analog scale. CoDAS 2016; 28(1): 53-8. [http://dx.doi.org/10.1590/2317-1782/20162015030] [PMID: 27074190]

[16] Hasson D, Bengt BA. Validation and findings comparing VAS vs. Likert scales for psychosocial measurements. Int Electron J Health Educ 2005; 8: 178-92.

[17] du Toit R, Pritchard N, Heffernan S, Simpson T, Fonn D. A comparison of three different scales for rating contact lens handling. Optom Vis Sci 2002; 79(5): 313-20.

[http://dx.doi.org/10.1097/00006324-200205000-00011] [PMID: 12035989] 
[18] Pearson EJ. Comfort and its measurement--a literature review. Disabil Rehabil Assist Technol 2009; 4(5): 301-10. [http://dx.doi.org/10.1080/17483100902980950] [PMID: 19565373]

[19] Rohrmann B. Empirische Studien zur Entwicklung von Antwortskalen für die sozialwissenschaftliche Forschung. Z Soz Psychol 1978; 9: $222-45$.

[20] van Laerhoven H, van der Zaag-Loonen HJ, Derkx BH. A comparison of Likert scale and visual analogue scales as response options in children's questionnaires. Acta Paediatr 2004; 93(6): 830-5. [http://dx.doi.org/10.1111/j.1651-2227.2004.tb03026.x] [PMID: 15244235]

[21] Hernández A, Espejo B, González-Romá V. The functioning of central categories Middle Level and Sometimes in graded response scales: Does the label matter? Psicothema 2006; 18(2): 300-6. [PMID: 17296048]

[22] Vigo DE, Ogrinz B, Wan L, et al. Sleep-wake differences in heart rate variability during a 105-day simulated mission to Mars. Aviat Space Environ Med 2012; 83(2): 125-30. [http://dx.doi.org/10.3357/ASEM.3120.2012] [PMID: 22303591]

[23] Heart rate variability: Standards of measurement, physiological interpretation and clinical use. Circulation 1996; 93(5): 1043-65. [http://dx.doi.org/10.1161/01.CIR.93.5.1043] [PMID: 8598068]

[24] Trimmel K. Sensitivity of HRV parameters including pNNxx proven by short-term exposure to $2700 \mathrm{~m}$ altitude $2011 ; 32(3)$ : 275-85.

[25] Trimmel M. Relationship of heart rate variability (HRV) parameters including pNNxx with the subjective experience of stress, depression, well-being, and every-day trait moods (TRIM-T): A pilot study. Ergonomics Open Journal 2015; 8: 32-7. [http://dx.doi.org/10.2174/1875934301508010032]

[26] Billman GE, Huikuri HV, Sacha J, Trimmel K. An introduction to heart rate variability: Methodological considerations and clinical applications. Front Physiol 2015; 6: 55.

[http://dx.doi.org/10.3389/fphys.2015.00055] [PMID: 25762937]

[27] Science of the Heart Exploring the Role fo the Heart in Human Performance. Boulder Creek, CA: Institute of HeartMath 2001.

[28] Lang PJ, Bradley MM, Cuthbert BN. International affective picture system (IAPS): Digitized photographs, instruction manual and affective ratings Technical Report A-6 Gainesville, FL: University of Florida 2005.

[29] Thie JF. Touch for Health The complete edition A practical guide to natural health with acupressure touch and massage 2005.

[30] Jacobson E. Progressive Relaxation. 2nd ed. Oxford, England: Univ. Chicago Press 1938.

[31] Nunnally JC, Bernstein IH. Psychometric Theory. 3rd ed. New York: McGraw-Hill 1994.

[32] Cousineau D, O’Brien F. Error bars in within-subject designs: A comment on Baguley (2012). Behav Res Methods 2014; 46(4): 1149-51. [http://dx.doi.org/10.3758/s13428-013-0441-z] [PMID: 24477859]

[33] Hebb DO. Drives and the C.N.S. (conceptual nervous system). Psychol Rev 1955; 62(4): 243-54. [http://dx.doi.org/10.1037/h0041823] [PMID: 14395368]

[34] Lang P. The application of psychophysiological methods to the study of psychotherapy and behavior change. In: Bergin A, Garfield S, Eds Handbook of Psychotherapy and Behavior Change: An Empirical Analysis. New York: Wiley 1971; pp. 75-125.

[35] Yerkes RM, Dodson JD. The relation of strength of stimulus to rapidity of habit-formation. J Comp Neurol Psychol 1908; 18 : 459-82. [http://dx.doi.org/10.1002/cne.920180503]

[36] Berlyne DE. Conflict, Arousal and Curiosity. New York: McGraw-Hill 1960 [http://dx.doi.org/10.1037/11164-000]

[37] Miller GA. The magical number seven plus or minus two: some limits on our capacity for processing information. Psychol Rev 1956; 63(2): 81-97. [http://dx.doi.org/10.1037/h0043158] [PMID: 13310704]

[38] Cowan N. The magical mystery four: How is working memory capacity limited, and why? Curr Dir Psychol Sci 2010; $19(1)$ : 51-7. [http://dx.doi.org/10.1177/0963721409359277] [PMID: 20445769]

[39] van Laerhoven H, van der Zaag-Loonen HJ, Derkx BH. A comparison of Likert scale and visual analogue scales as response options in children's questionnaires. Acta Paediatr 2004; 93(6): 830-5. [http://dx.doi.org/10.1111/j.1651-2227.2004.tb03026.x] [PMID: 15244235]

[40] González-Betanzos F, Leenen I, Lira-Mandujano J, Vega-Valero Z. The effect of the number of answer choices on the psychometric properties of stress Evaluar 2012; 12: 43-59.

[41] Trimmel M, Wright N, Backs RW. Psychophysiology in ergonomics: Preface to the Special Section. Hum Factors 2003; 45(4): 523-4. [http://dx.doi.org/10.1518/hfes.45.4.523.27091] [PMID: 15055458]

[42] Trimmel M, Fairclough S, Henning R. Psychophysiology in ergonomics. Appl Ergon 2009; 40(6): 963-4. [http://dx.doi.org/10.1016/j.apergo.2009.02.003] [PMID: 19278667]

(C) 2017 Trimmel and Trimmel.

This is an open access article distributed under the terms of the Creative Commons Attribution 4.0 International Public License (CC-BY 4.0), a copy of which is available at: https://creativecommons.org/licenses/by/4.0/legalcode. This license permits unrestricted use, distribution, and reproduction in any medium, provided the original author and source are credited. 